\title{
Animal Models of Psychosis: Current State and Future Directions
}

\author{
Alexandra D. Forrest $\cdot$ Carlos A. Coto $\cdot$ Steven J. Siegel
}

Published online: 25 March 2014

(C) Springer International Publishing AG 2014

\begin{abstract}
Psychosis is an abnormal mental state characterized by disorganization, delusions and hallucinations. Animal models have become an increasingly important research tool in the effort to understand both the underlying pathophysiology and treatment of psychosis. There are multiple animal models for psychosis, with each formed by the coupling of a manipulation and a measurement. In this manuscript we do not address the diseases of which psychosis is a prominent comorbidity. Instead, we summarize the current state of affairs and future directions for animal models of psychosis. To accomplish this, our manuscript will first discuss relevant behavioral and electrophysiological measurements. We then provide an overview of the different manipulations that are combined with these measurements to produce animal models. The strengths and limitations of each model will be addressed in order to evaluate its cross-species comparability.
\end{abstract}

Keywords Psychosis - Animal model · Behavior .

Electroencephalography $\cdot$ Transgenic mice $\cdot$ Pharmacological manipulation

\section{Table of Contents}

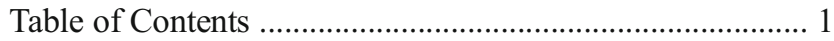

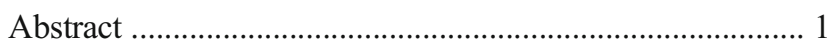

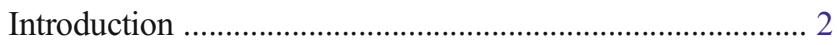

Definition of Psychosis .................................................... 2

Definition of an Animal Model ........................................ 2

A. D. Forrest · C. A. Coto · S. J. Siegel

Translational Neuroscience Program, Department of Psychiatry,

University of Pennsylvania, Philadelphia, PA 19104, USA

\section{S. J. Siegel $(\bowtie)$}

Translational Research Laboratories, University of Pennsylvania, Room 2202, 125S. 31st Street, Philadelphia, PA 19104, USA

e-mail: siegels@mail.med.upenn.edu

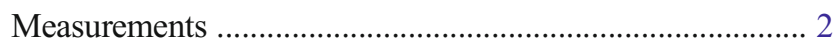

Behavioral Measures ....................................................... 2

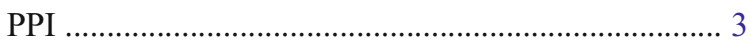

Latent Inhibition ................................................................. 3

Conditioned Avoidance Response ............................. 3

Stereotypy ............................................................. 3

Hyperactivity ................................................................... 4

Strengths and Weaknesses ............................................ 4

Electrophysiological Measures ............................................ 5

Event Related Potentials ............................................... 5

Mismatch Negativity ....................................................... 5

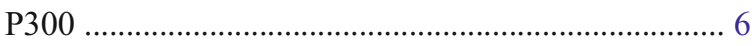

Strengths and Weaknesses ............................................. 6

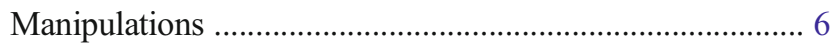

Pharmacological Manipulations ........................................ 6

Genetic Manipulations .......................................................... 6

Developmental Manipulations ............................................ 7

Environmental Manipulations ………………………….... 7

Strengths and Weaknesses ............................................. 7

Manipulations to Neurotransmitter Systems .......................... 8

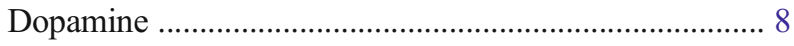

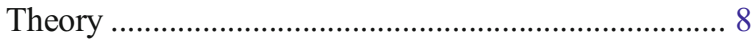

Pharmacological ........................................................ 8

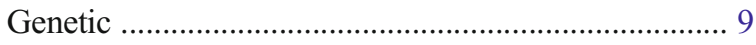

Strengths and Weaknesses .......................................... 9

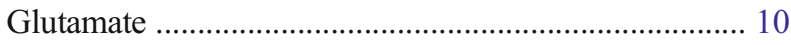

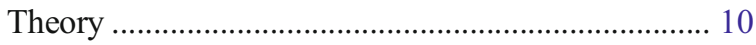

Pharmacological …………………………………... 10

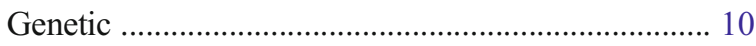

Strengths and Weaknesses .......................................... 11

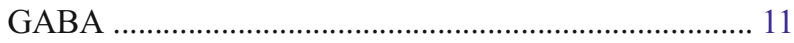

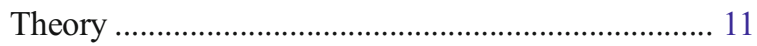

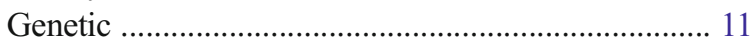

Strengths and Weaknesses .......................................... 11

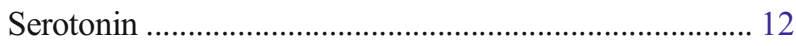

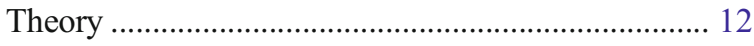

Pharmacological .......................................................... 12 
Genetic 12

Strengths and Weaknesses 12

Future Directions and Conclusion 12

Acknowledgements 35

Figure Legends 36

References 37

\section{Introduction}

Psychosis is a brain disease characterized by an abnormal mental state and a loss of contact with reality. In an effort to produce viable treatment options for psychosis, animal models have become increasingly important. Animal models are extremely useful and serve as an essential tool for investigating mechanisms and treatments for a variety of human disorders, including psychosis. In this manuscript, we summarize both the current state and future research directions of animal model approaches for studying psychosis.

Before delving into the topic of modern models of psychosis, it is important to note that this article will discuss psychosis in a holistic sense as it relates to several disorders. As such, this article will not discuss models limited to the pathophysiology of schizophrenia, bipolar disorder, or any other related diseases. It will focus purely on models related to psychosis. Furthermore, when a model is discussed in the context of a specific disorder, the model will only be discussed with reference to psychosis and not to the other aspects of that disorder and model, such as cognition and social function. The models of psychosis that will be discussed in this article involve both a manipulation and a measure. We will focus on a behavioral or physiological outcome, coupled to the manipulation that induced the psychotic state as the formation of a viable animal model.

\section{Definition of Psychosis}

Psychosis is a mental state characterized by a distortion of reality. Patients diagnosed with psychosis may present with one or more of the following symptoms: hallucinations, delusions, catatonia, disordered thoughts, or impaired social cognition. Psychosis is commonly seen in patients suffering from schizophrenia, bipolar disorder and Parkinson's disease. Furthermore, some surgery patients have brief episodes of postoperative psychosis. A study by van der Mast et al. reported that post-operative psychosis occurred in $13.5 \%$ of cardiac surgery patients [1].

\section{Definition of an Animal Model}

An animal model is an approximation of a specific human condition or disease. They are used in order to gain insight into the etiology of the disease or to develop treatment options. A model is formed by the combination of a manipulation and a measurement. The manipulation induces the state and the measurement offers a way to qualify or quantify the results of this induced change.

In order for an animal model to be a reliable model of a human condition there are several forms of validity that must be met: face validity, construct validity, predictive validity, internal validity, and external validity. Face validity indicates the cross-species comparability. It refers to the similarity between the state induced in the animal model and the symptoms observed in humans [2]. Construct validity refers to the accuracy of a test in measuring what it is proposed to measure [2]. Predictive validity is the capacity of a model to predict the criterion that is being studied. Internal validity refers to both the reliability and replicability of a study; it tests the specificity of models [2]. External validity is the extent to which the results obtained using a particular animal model can be generalized to a real-world population [2].

Cross-species comparability refers to the ability of the results of an animal model to be generalized to the human condition that it is trying to approximate. An animal model must exhibit a measureable similarity with the human ailment in question in order for the model to provide any valuable insight into a particular disease. As such, the cross-species comparability of each measurement and manipulation will be discussed as strengths in the relevant sections of this article.

Limitations, in reference to animal models, refer to any inaccuracies that may occur in the approximation of a specific condition. Despite the cross-species comparability that exists in many of the models presented in this manuscript, there are still many limitations to be addressed, as many of these manipulations and measures are not completely true to the state of psychosis they are attempting to model. These limitations will be addressed as weaknesses in the relevant areas of this manuscript.

\section{Measurements}

In this section, we will address both behavioral and electrophysiological measurements of psychosis. These measurements are used to both qualify and quantify effects of a manipulation in an animal model. Several relevant behavioral measurements will be discussed in this section. A comprehensive list will not be presented; rather, the most important examples will be discussed in detail.

\section{Behavioral Measures}

Behavioral measures are methods that attempt to quantify and interpret the actions of an animal. The underlying hypotheses 
are: that the action being evaluated informs the biology related to psychosis and/or; the animal's behavior is informative about some mental construct or process and/or; altering the animal behavior using a treatment is predictive of effects of that treatment in humans. The validity of these assumptions will be addressed individually within each section.

\section{PPI}

PPI is a measurement commonly used in schizophrenia models and is also useful for measurements in animal models of psychosis. In the PPI paradigm, subjects are exposed to a weak, often acoustic pre-stimulus followed 30-300 ms later by a stronger startle stimulus [3]. Physical response to the startle stimulus is measured and compared to the startle response when no pre-stimulus is used (Fig. 1). This difference provides a quantitative measure of motor inhibition that has been theoretically linked to a subject's neuronal inhibitory mechanisms. This link is largely based on the observation that alterations in the dopamine system, such as administration of amphetamine, cause a reduction of PPI. Additionally, PPI deficits observed in schizophrenia patients are correlated clinically with symptoms such as thought disorder and distractibility [3].

\section{Latent Inhibition}

Latent inhibition (LI) refers to a process by which noncontingent presentation of a stimulus diminishes the ability to enter into subsequent associations. Thus, the prior experience that a stimulus does not have a consequence makes it less likely that the brain will form an association with that stimulus later. LI is widely considered to relate to the cognitive abnormalities that characterize schizophrenia because it reflects an organism's ability to ignore irrelevant stimuli [4-7]. However, it also has been linked to psychosis based on the observation that medications that effectively treat psychosis, such as clozapine and haloperidol, restore latent inhibition across a variety of conditions [4, 5].

\section{Conditioned Avoidance Response}

In the conditioned avoidance response paradigm, an electric foot shock is paired with a conditioned stimulus of a tone or light. This will elicit a learned avoidance response so the animal can escape being shocked [8]. This link between the unconditioned and conditioned response is facilitated by dopamine, although several other neurotransmitters are thought to also play a role [9]. When this dopaminergic pathway is disrupted, one sees a decrease in the normal, appropriate avoidance response (i.e., the animal fails to escape). This assay for a reduction in dopamine activity has been used to determine the efficacy of many dopamine antagonists, including both typical and atypical antipsychotics such as haloperidol and risperidone [10-12]. Although this approach has been instructive in finding therapies that block dopamine type 2 receptors and therefore are effective for psychosis, those very same agents actually impair a normal self-preservation function. Thus, the major limitation to this behavioral model is that its predictive validity is at odds with normal function, as well as lacking construct validity related to psychosis.

\section{Stereotypy}

Stereotypy is characterized as repetitive behavior and has been noted in patients with psychosis and also in several
Fig. 1 Example of apparatus used to measure pre-pulse inhibition of startle in rodents
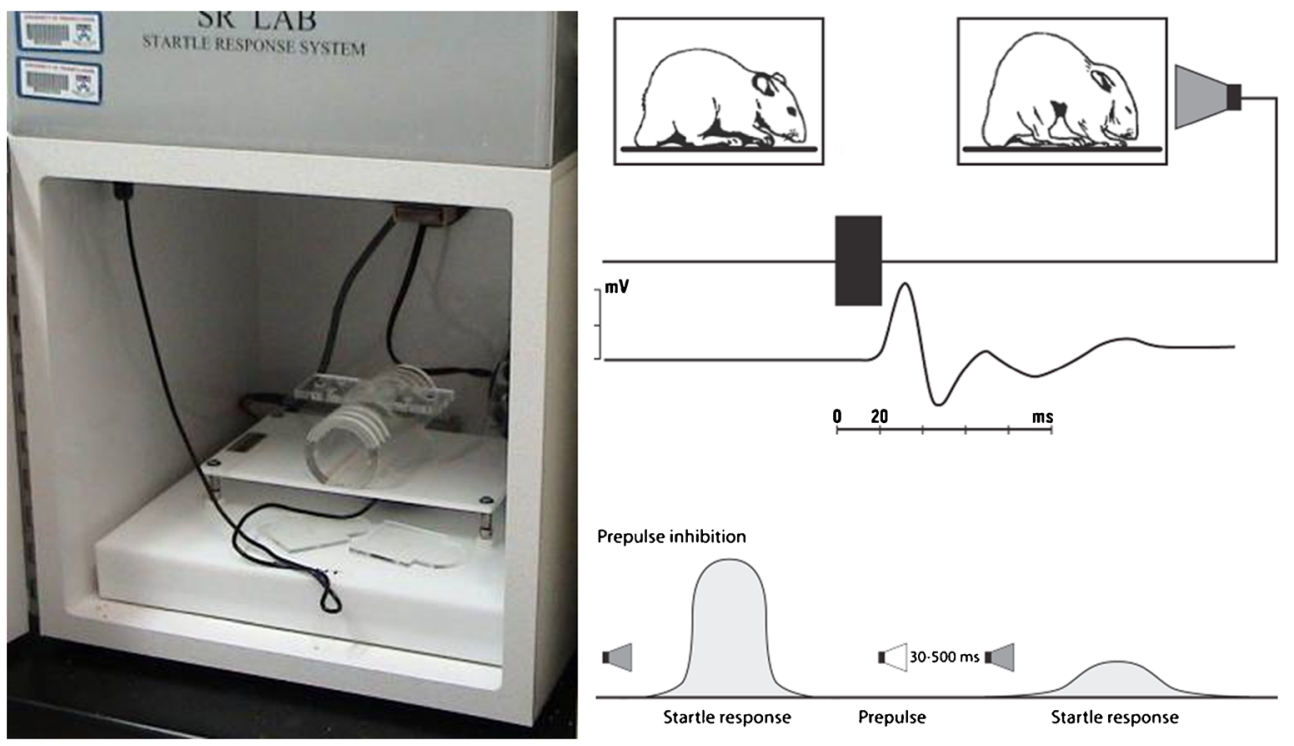
pharmacological human and animal models of psychosis [13-18]. Specific behaviors can vary depending on the drug or animal used and behaviors include, but are not limited to: repetitive licking, chewing, grooming, head movements, sniffing, circling, or climbing [17, 19-22]. The level of stereotypy can be determined through either recorded observation or the use of software programmed with predetermined criteria $[17,18,22]$. Stereotypy thus has been used as both a qualitative and quantitative measure in models of psychosis. For example, quantification of stereotyped behaviors may include rearing, as assessed using locomotor activity monitoring software, or by measuring time spent in repetitive movements [23]. The attenuation of these behaviors can also be used in evaluating the antipsychotic properties of compounds [24-26]. Alternatively, these same measures are likewise used to model motor aspects of schizophrenia such as tardive dyskinesia, as well as medication-induced side effects.

\section{Hyperactivity}

Hyperactivity in animal models is a behavioral measurement that has been associated with the agitation and disorganized behavior of psychosis [27]. Many early antipsychotics functioned as dopamine agonists; therefore hyperactivity has been hypothesized to originate from a hyper-dopaminergic state [28]. Hyperactivity, however, remains a consistent measurement even in models where dopamine release is not directly induced. It is suggested that the hyperactivity observed in such models is due to secondary effects on dopamine transmission [28-30]. The maintenance of hyperactivity in models that do not directly influence dopamine supports the idea of elevated dopamine neurotransmission being characteristic of psychosis, but not necessarily the source of psychosis [31-33].

Hyperactivity in mouse models was historically measured through first person observation. Presently, hyperactivity is measured through the use of computer software, yielding greater accuracy. In the former method, experimenters would conduct an open field test in which a grid was drawn on the floor and the experimenter would note every time a grid line was crossed by an animal, in order to calculate an ambulation score for locomotor activity [34]. Locomotor activity can now be measured using a grid of photo-beams at the bottom of a chamber, which is combined with software that determines the number of beam breaks $[35,36]$. Increased locomotor activity is often assumed to indicate a general level of hyperactivity $[35,36]$.

\section{Strengths and Weaknesses}

As a whole, behavioral measurements are limited in their ability to translate animal model measurements to humans.
This limitation is associated with several factors. The most general limitation stems from the inability to truly interpret the motivation or meaning of the vast majority of animal behaviors. For example, we often ascribe a set of constructs and/or goals to what an animal does, and why it does so. However, there are generally multiple interpretations. Obvious examples of this anthropomorphic fallacy are not limited to psychosis; rather, they are present across a wide variety of studies of normal and abnormal states. For example, the forced swim and tail suspension tests are used to evaluate antidepressant effects. In essence, the animal (generally a mouse) struggles to swim in a chamber filled with water, or climb its tail when attached to the wall with tape. In both cases, increasing the latency to stop trying is associated with an "antidepressant therapeutic" effect. However, in both cases, the animal's motivation and choice to stop trying can be seen in a diametrically different way. Since hanging a mouse by its tail is not harmful, and mice do float, a longer time struggling can also be seen as increasing the latency to learn that struggling is futile and a poor use of energy resources. That is to say, the behavior could just as easily be used as a way to assess for compounds that impair cognition. We will now return to the aforementioned psychosis related behavioral measures in order to describe similar pros and cons.

One of the primary advantages of PPI is its ability to be used similarly in mice, rats, and humans, because it is one of the few tests that is largely conserved across all vertebrate species [37]. There is excellent stability and high test-retest reliability of PPI across time in both rodents and humans, facilitating the use of withinsubjects and longitudinal designs. On the other hand, the construct validity between PPI and psychosis is quite limited. As such, its primary value has been as a screening tool for alterations of DA function, and therefore as a screening tool for DA antagonist medications for psychosis. There are also some minor logistical limitations that must be considered. PPI levels vary based on sex, both in humans and in rodents, and it can be difficult to compare within female subjects because PPI fluctuates throughout the menstrual cycle [38]. This however may pertain to multiple behavioral measures and is not specific to PPI.

One of the major strengths of the latent inhibition task is that it can be applied across many mammalian species. Several studies suggest that latent inhibition also fulfills criteria for construct, face and predictive validity in a variety of animal models relevant to schizophrenia [39-41]. Although the construct validity pertains primarily to cognitive deficits, the predictive validity for medication effects on positive symptoms of psychosis is better than for negative or cognitive symptoms [41, 42]. However, predictive validity for negative cognitive symptoms has been notoriously 
poor, as no agents to date have shown efficacy for either of these domains in humans.

\section{Electrophysiological Measures}

Electroencephalography (EEG) was the first physiological technique used to examine the brain by recording electric field potentials with the capability to reflect both the normal and abnormal electrical activity of the brain. Hans Berger, a German neurologist, recorded the first EEG in 1924. Eventually, EEG evolved into an indispensable method for studying cerebral information processing, particularly due to the introduction of source localization techniques and the decomposition of event-related activity into its frequency components. Conventionally, EEG is recorded from the scalp using electrodes affixed to specific scalp locations and is represented as changes in potential difference. The scalp EEG reflects the summated potentials from a large synchronously activated population of pyramidal cells in the cerebral cortex. These potentials are thought to originate primarily from excitatory and inhibitory neural electric activity, including action potential (AP) and postsynaptic potentials [43].

\section{Event Related Potentials}

Electroencephalography provides a method to investigate general function of the brain including its reaction to particular stimuli that will be represented as changes in the EEG, globally known as event-related potentials (ERP) or evoked potentials (EP). These event-related potentials are defined as the oscillatory brain responses that are triggered by the occurrence of particular stimuli (auditory, visual, or somatosensory). These voltage fluctuations also allow one to measure distinct stages in neural information processing. Moreover, ERPs reflect sub-cortical and cortical information processing in real time, and thus provide a useful tool for examining cognitive mechanisms in both normal brain function and disorderrelated impairments.

EEG recordings analogous to those described above can be obtained from a variety of rodent species. In mice, the characteristic positive and negative deflections of the EEG recording occur at approximately $40 \%$ the latency of equivalent human components [44-46]. Therefore, the P20, N40, P80 and P120 represent ERP deflections in mice analogous to the P50, N100, P200 and P300, respectively, in humans (Fig. 2). Some groups have analyzed P20 and N40 potentials as a single ERP component (termed the P20/ N40) in order to examine the effects of pharmacological, genetic and environmental manipulations on the general property of habituation. However, subsequent work has

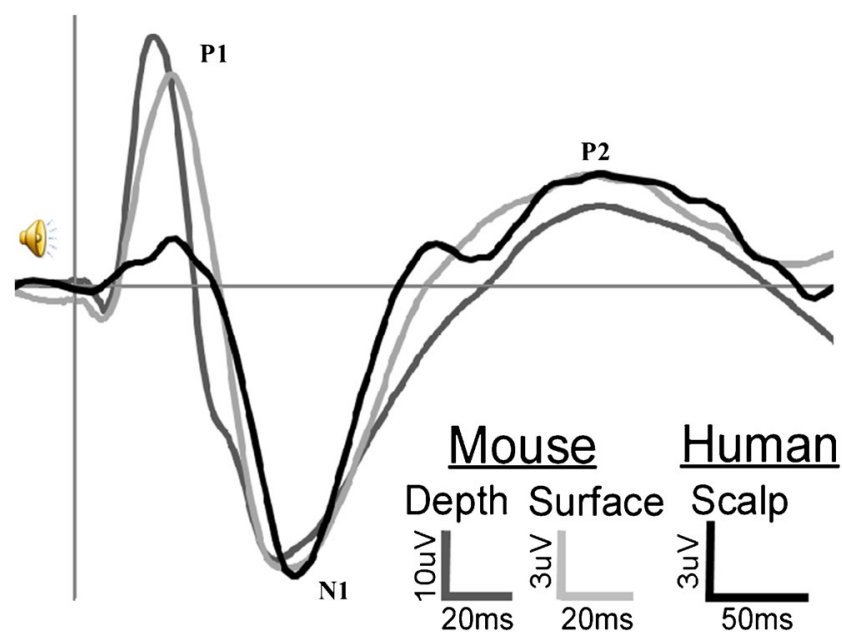

Fig. 2 Representative grand average auditory event related potential recordings from human scalp, mouse surface and mouse depth electrodes. Note that the overall pattern of event related activity is consistent across species and locations, with a prominent $\mathrm{P} 1, \mathrm{~N} 1$ and $\mathrm{P} 2$ components. These responses are termed "obligatory" as they occur in response to a simple tone or click in rodents, non-human primates or clinical populations. These components occur at $40 \%$ of the human latency in mouse. Thus, the P1 occurs at $20 \mathrm{~ms}$ in mouse and $50 \mathrm{~ms}$ in human, while the N1 and P2 occur at $40 \mathrm{~ms}$ and $80 \mathrm{~ms}$ in mouse and $100 \mathrm{~ms}$ and $200 \mathrm{~ms}$ in human respectively. Studies over the past decade demonstrate that each component in mouse shares psychometric and pharmacological response properties within the corresponding human ERP component, yielding excellent predictive validity

suggested that these two components are subject to independent effects by manipulations such as nicotine and ketamine treatment [44, 47-52].

\section{Mismatch Negativity}

The ability to detect, and adapt to, changes in auditory stimulus characteristics is basic as neuronal functions can be measured with ERPs in both humans and animals. Mismatch negativity (MMN) reflects the context-dependent information processing, required to compare a deviant incoming stimulus with the neural representation already stored in transient auditory memory [53]. When a string of tones with a specific regularity (sequence of homogeneous tones) is presented, the brain stores the features of this auditory stimulation in a short-duration neural memory trace [54]. While this echoic memory is still active, each new auditory input is compared to the existing trace for a break of regularity (deviant tone), which generates a neuronal adaptation giving rise to the MMN between 100 and $225 \mathrm{~ms}$ in humans [55]. MMN is most frequently elicited in an auditory oddball paradigm. A sequence of repetitive standard stimuli is randomly interrupted by a deviant oddball stimulus, which may differ in stimulus characteristics such as pitch, intensity, or duration. Generators are located in the 
auditory and frontal cortices $[56,57]$. Of particular importance, MMN is evoked irrespective of attention or awareness (e.g., present in comatose patients) [58]. In clinical neurosciences, MMN has been widely used in various applications, in particular in schizophrenia research, due to its good reproducibility and the ability to assess it without a task [59].

\section{P300}

Probably the most extensively studied long-latency ERP component is the P300 (also termed P3), a time-locked positive deflection emerging $250 \mathrm{~ms}$ to $500 \mathrm{~ms}$ after attending stimulus. First described by Sutton et al. in 1965, P300 is thought to reflect an information processing cascade when attentional and memory mechanisms are engaged [60]. Although related to the process of sensory stimulus mismatch detection, the P300 component represents an attention-driven memory comparison process, in which every incoming stimulus will be revised to detect possible stimulus feature modifications. According to whether changes are present or absent, the electrophysiological recordings will differ. If no change can be detected, only so- called obligate evoked potentials are recorded (N100; P200; N200). If a new stimulus is presented and the subject allocates attentional resources to the target, the neural stimulus representation is altered and the consequent update leads to the generation of P300 [60]. Similar to the MMN, the auditory P300 is elicited in context of an oddball paradigm, but in contrast to MMN elicitation the generation of P300 requires the test-taking person to be attentive and respond physically or mentally to the presented target. Commonly, subjects are instructed to either push a button following the infrequent target or to count deviants.

\section{Strengths and Weaknesses}

EEG in general and ERPs in particular are the most readily translatable measure across species. In contrast to behavior, one measures the exact same phenomenon across species and no interpretations of "meaning or intent" are required. Many studies have demonstrated that both mouse and human ERP components are similarly affected by certain pharmacological treatments and stimulus manipulations [61-63]. Thus, recording EEG and ERPs in preclinical studies provides the most translational model system for physiological deficits associated with psychosis.

Although electrophysiological measurements have the highest face and construct validity of any measure, it is less clear how such measures relate to clinical symptoms. Evidence for a link between these measures and cognition is beginning to emerge, but the association with psychosis per se is much weaker. Additionally, studies of the differences in the P300 observed across various patient populations have been highly variable [60]. Despite simplicity of the task, the cerebral mechanisms producing an ERP remain unclear [64-66].

\section{Manipulations}

In this section, we will discuss relevant manipulations used in animal models of psychosis, with reference to the different types of validity, generalizability, inconsistencies, and any confounding variables. Molecular mechanisms will be addressed within genetic and pharmacological manipulations, as these are the tools used to address the intra-cellular and inter-cellular signal transduction pathways that contribute to psychosis. As was the case with measurements, this section will not provide a comprehensive list, but rather a discussion of the most important manipulations.

\section{Pharmacological Manipulations}

Pharmacological models of psychosis are founded on the current understanding of the effects of drugs on various neurotransmitter systems. They rely on the observation that certain drugs induce behaviors that mimic or predict symptoms of psychosis in humans. Both acute and chronic doses of ketamine are widely used by investigators to disrupt glutamate signaling in order to model psychosis-like effects. For example, both the NMDA receptor-antagonists ketamine and PCP can cause a dissociative state reminiscent of disorganization as well as hallucinations. Similarly, amphetamine can cause a psychotic state in humans and is therefore given to animals to simulate the biological environment present in a psychotic state. Such pharmacological manipulations will be addressed in the following section regarding changes to specific neurotransmitter pathways.

\section{Genetic Manipulations}

Genetic models of psychosis are created through the disruption of a molecular genetic pathway that has been linked through association studies to a variety of psychotic states. A host of genetic manipulations have been combined with specific outcome measures to assess the extent to which alteration of a gene or signaling pathway is related to various behaviors and physiological phenomena. For example, alterations of NMDA receptor expression in mice leads to a number of behavioral and physiological changes noted above that are considered relevant to psychosis [62]. 
Genetic models noted represent both candidate gene and candidate pathway approaches. The former focus on genes that have been identified primarily through human association studies with a specific disease, e.g., schizophrenia. The latter is likely a more informative approach, and represents efforts to use genetic manipulations to dissect signaling pathways that contribute to the physiology of psychosis across a multitude of etiologies. This latter approach offers greater generalizability and is also likely more meaningful with respect to therapeutic development. We will not provide a comprehensive list of candidate gene models for specific disorders as these are discussed in detail elsewhere [67].

\section{Developmental Manipulations}

Developmental models of psychosis are founded upon a manipulation during the ontogeny of the animal that affects a developmental outcome, inducing a set of psychosisrelated behaviors and physiological changes. The manipulation induces a change that models the state of the human disease in the animal. Prenatal exposure to the cell division inhibitor methlazoxymethanol acetate (MAM) is one example of a developmental animal model of psychosis. Exposure to MAM at embryonic day 17 produces a pattern of brain atrophy in adult animals similar to that seen in human schizophrenia (i.e., cortical and hippocampal atrophy), increasing the face validity for a disease in which psychosis occurs [68]. However, these neural changes overlap with dysfunctions across a wide range of behavioral and cognitive domains affected in humans with schizophrenia, including measures sensitive to mesolimbic dopamine function and cognitive performance. Thus, MAM treated animals display impaired long-term memory, working memory and attentional flexibility, as well as increased responsiveness to measures related to psychosis following amphetamine as adults [69-73].

Lesion models of psychosis, though very limited, are a form of developmental model. This is the case because the lesion tends to be conducted early in development and affects a developmental course. In essence, a part of the animal's brain is lesioned in order to have the desired effect. Neonatal ventral hippocampal lesion (NHVL) is the most prominent example of inducing psychosis-related measures in rats. NVHL in rodents during early life has been shown to produce many of the behavioral measures related to psychotic symptoms in adulthood [74]. Relevant features of this model include amphetamine-induced hyperactivity and deficits in pre-pulse inhibition. These changes occur coincident with schizophrenia-like cellular and neuroanatomical changes, including reductions in parvalbumin expressing GABAergic interneurons; exaggerated response to glutamate agonist and antagonists, suggestive of a hypoglutamatergic state. Importantly, most of these changes occur only when the lesion is induced during the neonatal period, and do not occur in adult animals given similar lesions of the ventral hippocampus; suggesting that it is the altered neurodevelopmental environment that is the source of the changes observed in the model.

\section{Environmental Manipulations}

Environmental manipulations relevant to models of psychosis include any change to the living conditions of the animal that induce a set of behavioral or physiological measures related to psychosis. Similar to developmental manipulations, environmental conditions that can be linked to psychosis are relatively limited as compared to either pharmacological or genetic ones. However, we will address isolation rearing and stresses as two forms of environmental manipulations that have been relatively well characterized.

Isolation rearing during developmentally critical periods, such as infancy and adolescence, can serve as a stressor that can induce behaviors associated with psychosis [75-77]. The behavioral profile of mice and rats reared in isolation includes hyperactivity in response to novelty, and reduced pre-pulse inhibition. These however are not specific to psychosis, as social deficits, reduced conditioned response, impaired novel object recognition, and elevated aggression are also seen $[75$, 76, 78-84]. This behavioral profile could be the result of alterations to the HPA axis stress response, and studies have suggested that these alterations to the HPA axis are likely to be mediated by an elevated production of NADPH oxidase- 2 in response to the stress of social isolation [85-87]. Isolation rearing has also been shown to alter the signal transduction of glutamate, dopamine, and serotonin, three transmitters whose dysfunction has been implicated in psychosis [87-91]. In some instances this environmental model has been combined with a genetic model or pharmacological model to produce more robust results [77, 92].

A prolonged period of restraint has also been used to induce PPI deficits in mice [93]. Furthermore, adult mice prenatally exposed to stress through the restraint of their pregnant mother exhibited a constellation of psychosisrelated and non-psychosis related alterations including hyperactivity, reduced pre-pulse inhibition, social deficits, and impaired fear conditioning [94]. Other studies have modeled prenatal stress by exposing a pregnant mouse or rat to a variable stress paradigm in which the pregnant female is exposed to a range of stressors including restraint, a cold environment, food deprivation, forced swimming, 24 hours of light, an overcrowded cage, and foot shock over an a extended period of time [95-97]. The adult offspring that were prenatally exposed to this variable stress paradigm exhibit 
increased AMPH-induced locomotor activity, reduced prepulse inhibition, as well as a host of non-psychosis related behavioral and molecular phenotypes [95-97].

\section{Strengths and Weaknesses}

The major strength of the environmental approach is that it has one of the highest levels of translational validity from an etiological perspective. This is based on the current understanding that events that increase stress, and/or directly alter developmental processes lead to persistent psychotic states. The best evidence for this approach comes from epidemiological data showing small, but statistically significant and reliable, increases of psychotic illnesses among populations that experience early life and prenatal stressors, ranging from infection, to famine, death of the father during pregnancy, and war in general [98-101]. There is even stronger evidence that exposure to marijuana prior to and during adolescence can alter the normal developmental trajectory and lead to a permanent state of psychosis, reminiscent of schizophrenia [102, 103]. A major weakness of this approach stems from the nonspecific nature of the insults making it harder to link them to a singular mechanism of action. Both the pharmacological and environmental approaches are more translationally valid than genetic ones, which have offered limited insight into the mechanisms of psychosis after decades of intense effort and investment. Indeed, recent efforts now focus on the task of making sense of the enormous constellation of genetic data that has come out of the previous era of association and candidate gene approaches. Thus, pharmacological models offer the most power presently because they combine the strengths of translational validity and mechanistic clarity. However, genetic factors almost certainly modulate the effects of environmental changes, including exposure to drugs, and will therefore remain a necessary component of preclinical models.

\section{Manipulations to Neurotransmitter Systems}

This section will review theories of psychosis developed around specific neurotransmitters across pharmacological, environmental and genetic approaches.

\section{Dopamine}

\section{Theory}

Many of the models used in the study of psychosis have been based on the dopamine theory of psychosis, which postulates that psychosis arises from the deregulation of the dopamine system. The theory initially arose from the observation that many of the first antipsychotic medications antagonized dopamine receptors [104]. This deregulation could arise from the over-release of the transmitter, limited reuptake, or overexpression of specific dopamine receptors. This theory has been supported by studies in which humans with both preexisting, and no pre-existing psychosis, exhibit symptoms associated with psychoses after receiving a dopamine agonist $[105,106]$. For instance, the indirect dopamine agonist, amphetamine, produces a psychotic state in healthy individuals and exacerbates the symptoms of psychosis in patients [107, 108]. An excess of dopaminergic signaling is hypothesized to cause the positive symptoms of psychosis, particularly those associated with schizophrenia.

\section{Pharmacological}

\section{Amphetamine}

Amphetamine has been proposed to constitute a model of positive psychosis in general. Featherstone et al. summarize the effectiveness of amphetamine-induced models of schizophrenia as measured by PPI, locomotion and latent inhibition outcomes [71]. Sensitization of amphetamine can induce deficits in latent inhibition and PPI and in some doses causes increased locomotion [71]. Most studies use an escalating dose regimen in order to avoid the neurotoxic effects that could result from an initial high dose of amphetamine [71]. Studies have shown that this gradual increase does not produce neurotoxic effects when a high dose is reached, and therefore remains as a pharmacological modulator, rather than a lesion approach. Amphetamine-induced alterations of the auditory processing abnormalities common to psychotic conditions are well characterized in rodents. It has been consistently reported that amphetamine significantly disturbs ERP amplitude and habituation, in particular diminishing N40 and P80 components [109-112]. Furthermore, normal habituation in rats is disrupted following amphetamine administration. Amphetamine decreases N40 amplitude (the rat correlate of the human N100) and abolishes suppression of the neural response to the second stimulus, resembling the habituation disturbances seen in acutely psychotic, un-medicated patients [113].

\section{Methylphenidate}

Exposure to methylphenidate elicits increased locomotive responses as well as focused stereotypies, including repetitive head movements and oral behaviors [114]. These symptoms are also comparable to those seen in amphetamine-induced models of psychosis, as noted above. One key difference between methylphenidate-induced and amphetamineinduced models is that the former does not also elicit observable effects on serotonergic pathways. 


\section{Apomorphine}

Apomorphine is a non-selective dopamine agonist that is presently used in the treatment of Parkinson's disease. Of note, psychosis is among the known side effects of this agent, supporting the link between increased dopamine activity and psychosis [115]. Apomorphine has also been used in pharmacological studies to evaluate the success of drugs such as haloperidol and risperidone as antipsychotics [116, 117]. Specifically, apomorphine induces emesis in dogs through its dopamine agonist properties in the gastrointestinal system and therefore has been used as a behavioral measure of dopamine function [116]. This model was instrumental in screening compounds that were able to reduce emesis in dogs as potential candidates to reduce psychosis in humans [116, 117]. Although emesis in dogs has very poor construct or face validity for psychosis in humans, its use as a means to assess drugs as in vivo dopamine antagonists was instrumental in developing what remains the only effective treatment approach for psychosis, namely dopamine receptor type 2 (DR D2) antagonists.

\section{Genetic}

\section{Dominant-Negative DISC1 Transgenic Mice}

Disrupted in Schizophrenia 1 (DISC1) has been identified as a susceptibility gene to schizophrenia [118-120]. DominantNegative DISC1 transgenic mice express an altered form of DISC1 under the alpha CaMKII promoter [118]. The mice are characterized by several behavior abnormalities characteristic of psychosis including hyperactivity and disturbance of sensory-motor gating [118]. As a result, DISC1 has emerged as offering a potentially important molecular link in the etiology of psychosis and other related mental conditions, such as schizophrenia [120].

\section{COMT Transgenic Mice}

The Catechol-O-methyltransferase (COMT) is a key regulatory enzyme that degrades dopamine and thus controls dopamine availability $[121,122]$. In humans, a single nucleotide polymorphism leads to the substitution of a Valine in place of a Methionine at the 158/108 locus [123]. This modification causes a two-fold increase of COMT activity, thereby reducing dopamine levels [124]. Studies in mice with alterations in COMT activity are consistent with human data showing decreased ERP amplitude as well as reduced theta and gamma power among people with psychosis $[125,126]$. Specifically, COMT-Val transgenic mice displayed increased N40 latency and decreased P80 amplitude as well as reduced baseline theta and gamma power, indicating that COMT activity specifically alters long-latency components of the event-related response. More recent studies have demonstrated that the effect of COMT in schizophrenia is modified by epistatic interactions with several other genes, such that only a particular subset of genotypes results in dysfunction [127-132].

\section{$\mathrm{G}_{\mathrm{s}} \alpha$ Transgenic Mice}

$\mathrm{G}_{\mathrm{s}} \alpha$ transgenic mice express an isoform of the G-protein subunit $\mathrm{G}_{\mathrm{s}} \alpha$ that is constitutively active due to a point mutation $(\mathrm{Q} 227 \mathrm{~L})$ that prevents hydrolysis of bound GTP [133, 134]. Expression of the transgene is driven by the CaMKII $\alpha$ promoter, which restricts expression to postnatal forebrain neurons. Specifically, in situ hybridization studies indicate that the transgene is expressed in striatum, hippocampus and cortex but not cerebellum, thalamus or brainstem [134]. Previous studies indicate that $\mathrm{G}_{\mathrm{s}} \alpha$ transgenic mice have decreased amplitude of cortically generated N40, consistent with forebrain transgene expression and a schizophrenia endophenotype. As such, this transgenic model of sensory encoding deficits provides a foundation for identifying biochemical contributions to sensory processing impairments associated with schizophrenia and psychosis.

\section{Dysbindin-1 Mutant Mice}

DTNBP1 is a well-replicated vulnerability gene for both schizophrenia and glutamatergic dysfunction. DTNBP1 encodes the dystrobrevin-binding protein 1 (dysbindin-1) [135-137]. Reduction in dysbindin-1 expression has been found in the schizophrenia population, indicating that reduced dysbindin-1 protein levels may be a disease trait of schizophrenia $[136,138,139]$. Studies in mice with a loss of function mutation in the gene have confirmed that dysbindin-1 is involved in both glutamatergic and dopaminergic transmission in the hippocampal formation, and demonstrated that reduced working memory is replicated in the mouse model [140-143]. Thus, these anatomical and physiological data indicate that disruptions of dysbindin-1 may play a direct role in abnormal hippocampal circuit behavior [135, 138, 141, 143-146]. Several studies have evaluated the selective relationship between dysbindin polymorphisms and psychotic symptoms among people with psychiatric disorders. While one study reported an association with psychosis, the other found only a selective relationship with non-psychotic symptoms $[147,148]$.

\section{Strengths and Weaknesses}

The dopamine hypothesis of psychosis has remained the strongest and most supported theory over the past 60 years. Evidence supports that increased dopamine signaling is necessary and sufficient to create psychotic states in humans. The 
bulk of data indicating that a DA signaling deficit is necessary for psychosis relates to the ability to stop psychotic symptoms in schizophrenia using DA antagonists. Similarly, these same compounds (e.g., dopamine antagonists), are highly effective in reducing or eliminating psychotic symptoms across a host of other medical conditions, including post anesthesia delirium, psychotic depression, and epilepsy-related psychosis, just to name a few. Indeed, DA antagonists remain a highly effective treatment for psychosis, regardless of the etiology or primary pathophysiology of the causative state or disorder. Complementary evidence from drug abuse with compounds that augment or mimic DA (e.g., cocaine and amphetamine), as well as treatment of affective (e.g. bupropion) and motor disorders (e.g., ropinirole) with dopamine agonists, also indicate that increased DA availability is sufficient to cause psychotic symptoms.

\section{Glutamate}

\section{Theory}

Glutamate is the major excitatory (agonist) neurotransmitter in the human brain. NMDAR antagonists as models of psychosis became of great interest because these antagonists cover the complete spectrum of schizophrenia symptoms: positive (paranoia, agitation, and auditory hallucinations); negative (apathy, thought disorder, social withdrawal); and cognitive symptoms (impaired working memory) [149]. NMDA receptor antagonizing drugs have also been reported to induce psychosis-like alteration of event-related potentials, such as reduced P300 and MMN amplitude [150, 151]. In line with human studies, animals treated with NMDAR antagonists exhibit similar electrophysiological alterations, coincident with behavioral changes related to psychosis. Taken together, these aspects prompted researchers to increasingly employ pharmacological NMDAR blockade as a disease model [152]. Thus, the following section describes glutamatergic theories of psychosis based on using ketamine, PCP, and MK801 in humans, non-human primates and rodents.

\section{Pharmacological}

\section{Ketamine}

Schizophrenia patients treated with ketamine experience an exacerbation of positive and negative systems, suggesting that NMDAR antagonists affect a brain system that is already vulnerable in psychosis [153]. Similar to healthy humans, animals treated with ketamine exhibit behavioral and electrophysiological features that closely resemble psychosis. For example, acute ketamine administration decreases the amplitude of the mouse and rat N40 and P80, mimicking psychosis- like abnormalities on those components in humans [44, 50, 112]. Furthermore, mice undergoing 14 days of daily ketamine administration showed lasting effects, such as decreased N40 amplitude [50]. Reduced ability to detect changes in the auditory environment, as measured by EEG, is a further characteristic of psychosis that results from ketamine in rodents. While some studies have reported that ketamine disrupts cortically generated ERPs, others observed no significant effects [154-156].

\section{MK 801}

MK-801 (Dizocilpine) is a noncompetitive NMDA antagonist, like ketamine and phencyclidine, which has been used to induce phenotypes consistent with other animal models of psychosis. One of the most characteristic phenotypes observed with this pharmacological model has been deemed "popping" and denotes the incidents of explosive jumping in mice $[157,158]$. MK-801 induced dose-dependent stereotypies in rodents have included repetitive head weaving (lateral head movements), rolling, sniffing, piloerection, rearing, backpedaling and circling [23, 159-161]. Another study concluded that MK-801 treated rats with the circling stereotypy demonstrate face validity with that seen in human psychotic patients [162]. Furthermore, MK-801 treated animals have also shown an increase in locomotor activity and a reduction in sensory ERPs as seen in other models of psychosis [159, 163-165]. Importantly, exposure to NMDAR antagonists leads to increased baseline EEG power in the gamma range (above $30 \mathrm{~Hz}$ ), and a concomitant decrease in the power of evoked gamma oscillations [166, 167]. This modulation of both resting and evoked gamma power is analogous with the reduced gamma signal-to-noise ratio, and the shift from low frequency to high frequency activity observed in schizophrenia [167].

\section{Phencyclidine}

Phencyclidine (PCP) is another non-competitive NMDA receptor antagonist used in creating a pharmacological animal model of psychosis. Similar to previous models discussed, PCP has been shown to induce hyperactivity and reduced prepulse inhibitions in animals [168-170]. As an NMDAR antagonist, PCP induces stereotypies that are similar to those seen in the MK-801 pharmacological model and include: sniffing, rearing, gagging, weaving, backpedaling, grooming, stereotyped searching, circling, and repetitive head movements [171-173]. Studies have also found that PCP inhibits the event related P1 and N1 potentials [174]. Mice have also demonstrated an increase in resting gamma power after an injection of PCP [175]. 


\section{Genetic}

Disturbance of the NRG1 Signaling Pathway

NRG-1 and ErbB2/B4 have both been identified as susceptibility genes for schizophrenia. The NRG-1 gene encodes for the ligand Neuregulin, and the ErbB2/B4 genes encode receptors for this ligand. While the neuronal cell layers of ErbB2/ B4 knockout mice appear to develop normally, these mutations cause reduced dendritic spine maturation and reduced transport of glutamate receptors to the neuronal membrane [176]. Disturbance in the NRG-1 gene also has been associated with NMDA receptor hypo-function [177-180]. One study of these transgenic mice utilized auditory ERPs as an electrophysiological measurement [181]. This study used the NRG1 transgenic model in which all three major types of NRG1 have a partial deletion of the EGF-like domain. These NRG1 heterozygote mice displayed disrupted mismatch negativity similar to that observed in psychosis. As such, transgenic models have played a crucial role in determining the function of these gene products, particularly due to the limited availability and usefulness of postmortem human tissues.

\section{NR1 Hypomorphic Mice}

NR1 is an obligatory subunit of the NMDA receptor, and therefore reduction of this protein broadly effects NMDAR mediated glutamate transmission. NR1 hypomorphic mice express from $5 \%$ to $10 \%$ of the normal NR1 protein [182]. Several studies have reported behavioral abnormalities in these mice that are also found in both schizophrenia and psychosis. Since then, NR1 hypomorphic mice have been considered as a translation model for these conditions. Of note, NMDAR-hypofunction is thought to contribute to social, cognitive, and gamma (30-80 Hz) oscillatory abnormalities, phenotypes common to these disorders. However, circuit-level mechanisms underlying such deficits remain unclear.

\section{Strengths and Weaknesses}

The glutamate hypothesis of schizophrenia has become increasingly popular, largely with respect to treatment-resistant negative and cognitive symptoms. However, these treatment resistant domains are less pertinent to consideration of psychosis per se. Therefore, we will limit the following discussion to the so-called positive symptoms, broadly defined, of psychosis. The strongest evidence that alterations in glutamate signaling can contribute to psychosis comes from the effects of NMDA antagonist drugs of abuse in humans. Specifically, ketamine (Special K) or phencyclidine (angel dust) abuse can result in a lasting state of disorientation and bizarre behaviors that resemble illness related psychosis. Animal models using
NMDA antagonists also provide some support for the role of altered glutamate signaling in the psychotic process. However, this is largely limited to hyperactivity following low doses of NMDAR antagonists. Alternatively, there has been virtually no evidence that medications that alter glutamate signaling have any effectiveness for treating psychosis.

\section{GABA}

\section{Theory}

Most recently, the role of alterations in Gamma Aminobutyric Acid (GABA) signaling has been considered as a contributing factor in schizophrenia. There are several lines of evidence to support this hypothesis. First, a series of anatomical post mortem studies in schizophrenia have demonstrated alterations in the number of GABAergic cells. Additionally, multiple studies have shown that people with schizophrenia have elevated resting (i.e., baseline or default network) brain activity, suggesting a disinhibition phenotype. Furthermore, studies in non-human preclinical models demonstrate that exposure to glutamate antagonists also causes increased network activity. This in turn has been proposed to be due to a selective effect of the NMDAR antagonist drugs on glutamate receptors on GABAergic interneurons. Taken together, these data led to a hypothesis that there is reduced GABA-mediated inhibitory tone, due to a reduction of excitatory drive to interneurons.

\section{Genetic}

\section{GAT1 Knockout Mice}

A recent study found that GABA transporter 1 (GAT1) knockout mice exhibited behavioral phenotype associated with psychosis. These knockout mice displayed hyperactivity, increased sensitivity to psychotomimetic drugs, exaggerated responses to novel objects, impaired novel object recognition, and reduced pre-pulse and latent inhibition [183].

\section{Strengths and Weaknesses}

As noted above, much of the evidence relating GABA to psychosis is based on a constellation of anatomical data in schizophrenia, and interpretation of physiological data. However, there is little if any direct evidence for this hypothesized mechanism, beyond the initial anatomical data. Recent studies, investigating the effects of reduced NMDA receptor expression directly on either GABAergic cells or on excitatory pyramidal cells, suggest that the disinhibition model may not be correct. Specifically, reducing NMDAR mediated glutamate signaling on excitatory pyramidal cells leads to increased network excitability, reminiscent of either schizophrenia or exposure to NMDA antagonists. Thus, it now appears that 
directly altering the excitatory inputs on pyramidal (glutamatergic) neurons causes those very neurons to increase their firing rate. This in turn appears to be due to alterations in inherent membrane properties [184]. As such, the longstanding assumptions about disinhibition via GABAergic cells over the previous decade may not be valid [185].

\section{Serotonin}

\section{Theory}

The potential role of altered serotonin signaling in psychosis stems from the observation that several hallucinogenic compounds, such as Psilocybin (the active compound in mushrooms), mescaline (the active compound in peyote), and Lysergic Acid Diethylamide (LSD), bind to and activate various forms of serotonin receptors. While such observations suggest that selective activations of serotonin systems are capable of inducing psychosis, several of these compounds are also thought to activate dopamine receptors.

\section{Pharmacological}

Few specific pharmacological manipulations of the serotonin pathway exist. Pharmacological models of psychosis using solely compounds that modulate 5HT receptors are less ubiquitous than the previously discussed pharmacological models. DOI (2,5-dimethoxy-4-iodoamphetamine) is a 5HT 2A receptor agonist that has been used to induce head twitching in mice as a model with predictive validity for psychosis and hallucination [158]. LSD, DMT (Dimethyltryptamine), mescaline, and psilocybin are also 5HT 2A receptor agonists that have been able to produce positive symptoms of psychosis in humans [186-189]. However, there is not an abundance of studies that have used these compounds to produce animal models of psychosis. One study found that chronic administration of LSD at low doses induced behaviors such as hyperactivity and social deficits [35]. DMT has also caused deficits in mismatch negativity generation [156]. Due to the effects of these compounds on human subjects and the affinity of certain antipsychotics to $5 \mathrm{HT}$ receptors, dysfunction in 5HT signaling has been implicated alongside glutamate and dopamine [190-196].

\section{Genetic}

\section{5-HT 1A Receptor Knockout Mice}

5-HT 1A receptor knockout mice have exhibited relatively increased AMPH-induced locomotor activity. However, this manipulation demonstrated no change in pre-pulse inhibition and a reduction in the effect of the hallucinogen 5-MeO-DMT, making it less fitting as a model psychosis [197].

\section{Alteration to the Serotonin Transporter Gene}

The STin2 polymorphism of the serotonin transporter gene (SERT) has been associated with psychosis in humans, while SERT knockout mice have been recognized as a model of impaired emotional control [198, 199]. Impaired SERT function would theoretically result in elevated serotonin in the synaptic cleft and could possibly produce psychotic symptoms similar to those observed with 5HT 2A agonist [187, 200]. Future studies should explore whether this SERT knockout model could be related to psychosis.

Strengths and Weaknesses

As noted above, several lines of research suggest that primary alterations of serotonergic systems can create a psychotic state in humans, or produce animal behaviors that are associated with psychosis in humans. The greatest limitation to the link between serotonin systems and endogenous psychosis in humans comes from the lack of effectiveness of serotoninergic agents in treating the symptoms. For example, multiple agents have been created based on the hypothesis that adding activity at serotonin receptors would improve antipsychotic efficacy. However, this has been clearly disproven, as none of these agents are different (at least not better) than dopamine antagonists that lack serotonergic activity.

\section{Future Directions and Conclusion}

Recent years have seen an explosion of effort focused on the non-psychotic symptoms in schizophrenia and related disorders. Yet, there is little understanding of the basic mechanism of psychosis, as well as how those mechanisms relate to other illness domains. There are numerous animal models of psychosis that currently exist and the challenge remains to find common, overlapping mechanisms of psychosis pathophysiology that result from a wide array of etiologies.

Acknowledgements Funding provided by 5R01MH074672 -04 (S. J. Siegel) and 5R01DA023210-02 (S. J. Siegel). Support for A.D. Forrest and C.A. Coto provided by an undergraduate educational core training grant as part of 1P50MH096891-01 (R. E, Gur Center PI; S. J. Siegel Education Core PI). The authors wish to thank former members of the Siegel lab who contributed helpful guidance and comments.

\section{Compliance with Ethics Guidelines}

Conflict of Interest Carlos Coto declares no conflicts of interest. Steven Siegel received grants from the NIMH, NIDA and Boerhing Engleheim Astellas. Siegel received honoraria and travel expenses 
covered from Boehringer Englehiem. Siegel received royalties from NuPathe, and a patent for NuPathe.

Alexandra Forrest has no conflicts of interest to declare.

Human and Animal Rights and Informed Consent This article does not contain any studies with human or animal subjects performed by the author.

\section{References}

1. van der Mast RC et al. Incidence of and preoperative predictors for delirium after cardiac surgery. J Psychosom Res. 1999;46(5):479-83.

2. Geyer MA, Markou A. Animal models of psychiatric disorders, Psychopharmacology: The 4th Generation of Progress, F.E. Bloom and D.J. Kupfer, Editors. 1995, Raven Press: New York, NY.

3. Turetsky BI et al. Neurophysiological endophenotypes of schizophrenia: the viability of selected candidate measures. Schizophr Bull. 2007;33(1):69-94.

4. Arad M, Weiner I. Disruption of latent inhibition induced by ovariectomy can be reversed by estradiol and clozapine as well as by coadministration of haloperidol with estradiol but not by haloperidol alone. Psychopharmacology (Berlin). 2009;206(4):731-40.

5. Arad M, Weiner I. Contrasting effects of increased and decreased dopamine transmission on latent inhibition in ovariectomized rats and their modulation by 17 beta-estradiol: an animal model of menopausal psychosis? Neuropsychopharmacology. 2010;35(7):157082.

6. Hemsley DR. A simple (or simplistic?) cognitive model for schizophrenia. Behav Res Ther. 1993;31(7):633-45.

7. Gray NS, Snowden RJ. The relevance of irrelevance to schizophrenia. Neurosci Biobehav Rev. 2005;29(6):989-99.

8. Shannon HE et al. Muscarinic receptor agonists, like dopamine receptor antagonist antipsychotics, inhibit conditioned avoidance response in rats. J Pharmacol Exp Ther. 1999;290(2):901-7.

9. Wadenberg ML, Hicks PB. The conditioned avoidance response test re-evaluated: is it a sensitive test for the detection of potentially atypical antipsychotics? Neurosci Biobehav Rev. 1999;23(6):85162.

10. Wadenberg MG et al. Antagonism at 5-HT(2A) receptors potentiates the effect of haloperidol in a conditioned avoidance response task in rats. Pharmacol Biochem Behav. 2001;68(3):363-70.

11. Shannon HE et al. Xanomeline, an $M(1) / M(4)$ preferring muscarinic cholinergic receptor agonist, produces antipsychotic-like activity in rats and mice. Schizophr Res. 2000;42(3):249-59.

12. Siuciak JA et al. Inhibition of the striatum-enriched phosphodiesterase PDE10A: a novel approach to the treatment of psychosis. Neuropharmacology. 2006;51(2):386-96.

13. Frith CD, Done DJ. Stereotyped responding by schizophrenic patients on a two-choice guessing task. Psychol Med. 1983;13(4): 779-86.

14. Brady KT et al. Cocaine-induced psychosis. J Clin Psychiatry. 1991;52(12):509-12.

15. Robertson A, MacDonald C. Atypical neuroleptics clozapine and thioridazine enhance amphetamine-induced stereotypy. Pharmacol Biochem Behav. 1984;21(1):97-101.

16. Murray TF, Horita A. Phencyclidine-induced stereotyped behavior in rats: dose response effects and antagonism by neuroleptics. Life Sci. 1979;24(24):2217-25.

17. Fetsko LA, Xu R, Wang YY. Alterations in D1/D2 synergism may account for enhanced stereotypy and reduced climbing in mice lacking dopamine D2L receptor. Brain Res. 2003;967(1-2):191200.
18. Nunes EA et al. Effects of pregabalin on behavioral alterations induced by ketamine in rats. Rev Bras Psiquiatr. 2012;34(3):329-33.

19. Martin RS et al. Effects of cannabinoid receptor ligands on psychosis-relevant behavior models in the rat. Psychopharmacology (Berlin). 2003;165(2):128-35.

20. Andine $\mathrm{P}$ et al. Characterization of $\mathrm{MK}-801$-induced behavior as a putative rat model of psychosis. J Pharmacol Exp Ther. 1999;290(3):1393-408.

21. Waters KA et al. Effects of the selective 5-HT7 receptor antagonist SB-269970 in animal models of psychosis and cognition. Behav Brain Res. 2012;228(1):211-8.

22. Atkins AL et al. Stereotypic behaviors in mice selectively bred for high and low methamphetamine-induced stereotypic chewing. Psychopharmacology (Berlin). 2001;157(1):96-104.

23. Hitri A et al. Differentiation between MK-801- and apomorphineinduced stereotyped behaviors in mice. Clin Neuropharmacol. 1993;16(3):220-36.

24. Gattaz WF, Schummer B, Behrens S. Effects of zotepine, haloperidol and clozapine on MK-801-induced stereotypy and locomotion in rats. J Neural Transm Gen Sect. 1994;96(3):227-32.

25. Burris KD et al. Aripiprazole, a novel antipsychotic, is a highaffinity partial agonist at human dopamine D2 receptors. J Pharmacol Exp Ther. 2002;302(1):381-9.

26. Machado MS et al. An organic selenium compound attenuates apomorphine-induced stereotypy in mice. Neurosci Lett. 2006;410(3):198-202.

27. Powell SB, Zhou X, Geyer MA. Prepulse inhibition and genetic mouse models of schizophrenia. Behav Brain Res. 2009;204(2): 282-94.

28. Gerber DJ et al. Hyperactivity, elevated dopaminergic transmission, and response to amphetamine in M1 muscarinic acetylcholine receptordeficient mice. Proc Natl Acad Sci U S A. 2001;98(26):15312-7.

29. Rodvelt KR et al. Ketamine induces hyperactivity in rats and hypersensitivity to nicotine in rat striatal slices. Pharmacol Biochem Behav. 2008;91(1):71-6.

30. Gray L et al. Role of muscarinic receptors in the activity of Ndesmethylclozapine: reversal of hyperactivity in the phospholipase C knockout mouse. Behav Pharmacol. 2008;19(5-6):543-7.

31. de Bartolomeis A, Fiore G, Iasevoli F. Dopamine-glutamate interaction and antipsychotics mechanism of action: implication for new pharmacological strategies in psychosis. Curr Pharm Des. 2005;11(27):3561-94.

32. Stone JM et al. Altered relationship between hippocampal glutamate levels and striatal dopamine function in subjects at ultra high risk of psychosis. Biol Psychiatry. 2010;68(7):599-602.

33. Seeman P. All roads to schizophrenia lead to dopamine supersensitivity and elevated dopamine D2(high) receptors. CNS Neurosci Ther. 2011;17(2):118-32.

34. Kitahama K, Valatx JL. Strain differences in amphetamine sensitivity in mice. II. Overcompensation of paradoxical sleep after deprivation in two C57 strains. Psychopharmacology (Berlin). 1979;66(3):291-5.

35. Marona-Lewicka D, Nichols CD, Nichols DE. An animal model of schizophrenia based on chronic LSD administration: old idea, new results. Neuropharmacology. 2011;61(3):503-12.

36. Wieronska JM et al. The GABA B receptor agonist CGP44532 and the positive modulator GS39783 reverse some behavioural changes related to positive syndromes of psychosis in mice. Br J Pharmacol. 2011;163(5):1034-47.

37. Geyer MA, Mcllwain KL, Paylor R. Mouse genetic models for prepulse inhibition: an early review. Mol Psychiatry. 2002;7(10): 1039-53.

38. Aasen I, Kolli L, Kumari V. Sex effects in prepulse inhibition and facilitation of the acoustic startle response: implications for pharmacological and treatment studies. J Psychopharmacol. 2005;19(1): $39-45$. 
39. Ellenbroek BA, Cools AR. Animal models with construct validity for schizophrenia. Behav Pharmacol. 1990;1(6):469-90.

40. Lubow RE. Construct validity of the animal latent inhibition model of selective attention deficits in schizophrenia. Schizophr Bull. 2005;31(1):139-53.

41. Weiner I. The "two-headed" latent inhibition model of schizophrenia: modeling positive and negative symptoms and their treatment. Psychopharmacology (Berlin). 2003;169(3-4):257-97.

42. Weiner I, Arad M. Using the pharmacology of latent inhibition to model domains of pathology in schizophrenia and their treatment. Behav Brain Res. 2009;204(2):369-86.

43. Dietrich A, Kanso R. A review of EEG, ERP, and neuroimaging studies of creativity and insight. Psychol Bull. 2010;136(5):822-48.

44. Connolly PM et al. The effects of ketamine vary among inbred mouse strains and mimic schizophrenia for the P80, but not P20 or N40 auditory ERP components. Neurochem Res. 2004;29(6):1179-88.

45. Siegel SJ et al. Effects of strain, novelty, and NMDA blockade on auditory-evoked potentials in mice. Neuropsychopharmacology. 2003;28(4):675-82.

46. Maxwell CR et al. Effects of chronic olanzapine and haloperidol differ on the mouse N1 auditory evoked potential. Neuropsychopharmacology. 2004;29(4):739-46.

47. Stevens KE, Wear KD. Normalizing effects of nicotine and a novel nicotinic agonist on hippocampal auditory gating in two animal models. Pharmacol Biochem Behav. 1997;57(4):869-74.

48. Simosky JK, Freedman R, Stevens KE. Olanzapine improves deficient sensory inhibition in DBA/2 mice. Brain Res. 2008;1233:12936.

49. Simosky JK et al. Clozapine improves deficient inhibitory auditory processing in DBA/2 mice, via a nicotinic cholinergic mechanism. Psychopharmacology (Berlin). 2003;165(4):386-96.

50. Maxwell CR et al. Ketamine produces lasting disruptions in encoding of sensory stimuli. J Pharmacol Exp Ther. 2006;316(1): 315-24.

51. Metzger KL et al. Effects of nicotine vary across two auditory evoked potentials in the mouse. Biol Psychiatry. 2007;61(1):23-30.

52. Rudnick ND et al. Role of beta2-containing nicotinic acetylcholine receptors in auditory event-related potentials. Psychopharmacology (Berlin). 2009;202(4):745-51.

53. Bomba MD, Pang EW. Cortical auditory evoked potentials in autism: a review. Int J Psychophysiol. 2004;53(3):161-9.

54. Ulanovsky $\mathrm{N}$ et al. Multiple time scales of adaptation in auditory cortex neurons. J Neurosci. 2004;24(46):10440-53.

55. Naatanen R. Mismatch negativity (MMN): perspectives for application. Int J Psychophysiol. 2000;37(1):3-10.

56. Alho K. Cerebral generators of mismatch negativity (MMN) and its magnetic counterpart (MMNm) elicited by sound changes. Ear Hear. 1995;16(1):38-51.

57. Gomot $\mathrm{M}$ et al. Maturation of frontal and temporal components of mismatch negativity (MMN) in children. Neuroreport. 2000;11(14): 3109-12.

58. Fischer JE, Stallmach T, Fanconi S. Adrenal crisis presenting as hypoglycemic coma. Intensive Care Med. 2000;26(1):105-8.

59. Garrido MI et al. The mismatch negativity: a review of underlying mechanisms. Clin Neurophysiol. 2009;120(3):453-63.

60. Polich J. Updating P300: an integrative theory of P3a and P3b. Clin Neurophysiol. 2007;118(10):2128-48.

61. Amann LC et al. In vitro-in vivo correlations of scalable PLGArisperidone implants for the treatment of schizophrenia. Pharm Res. 2010;27(8):1730-7.

62. Gandal MJ et al. Gamma synchrony: towards a translational biomarker for the treatment-resistant symptoms of schizophrenia. Neuropharmacology. 2012;62(3):1504-18.

63. Gandal MJ et al. A novel electrophysiological model of chemotherapy-induced cognitive impairments in mice. Neuroscience. 2008;157(1):95-104.
64. Jongsma ML et al. Expectancy effects on omission evoked potentials in musicians and non-musicians. Psychophysiology. 2005;42(2):191-201.

65. Linden DE. The p300: where in the brain is it produced and what does it tell us? Neuroscientist. 2005;11(6):563-76.

66. Soltani M, Knight RT. Neural origins of the P300. Crit Rev Neurobiol. 2000;14(3-4):199-224.

67. Birnbaum R, Weinberger DR. Functional neuroimaging and schizophrenia: a view towards effective connectivity modeling and polygenic risk. Dialogues Clin Neurosci. 2013;15(3):279-89.

68. Talamini LM et al. Methylazoxymethanol acetate-induced abnormalities in the entorhinal cortex of the rat; parallels with morphological findings in schizophrenia. Brain Res. 1998;789(2):293-306.

69. Gourevitch $\mathrm{R}$ et al. Working memory deficits in adult rats after prenatal disruption of neurogenesis. Behav Pharmacol. 2004;15(4):287-92.

70. Fiore $\mathrm{M}$ et al. Long-lasting effects of prenatal MAM treatment on water maze performance in rats: associations with altered brain development and neurotrophin levels. Neurotoxicol Teratol. 2002;24(2):179-91.

71. Featherstone RE, Kapur S, Fletcher PJ. The amphetamine-induced sensitized state as a model of schizophrenia. Prog Neuropsychopharmacol Biol Psychiatry. 2007;31(8):1556-71.

72. Featherstone RE et al. Gestational methylazoxymethanol acetate treatment impairs select cognitive functions: parallels to schizophrenia. Neuropsychopharmacology. 2007;32(2):483-92.

73. Moore $\mathrm{H}$ et al. A neurobehavioral systems analysis of adult rats exposed to methylazoxymethanol acetate on E17: implications for the neuropathology of schizophrenia. Biol Psychiatry. 2006;60(3): 253-64.

74. Francois $J$ et al. Selective reorganization of GABAergic transmission in neonatal ventral hippocampal-lesioned rats. Int J Neuropsychopharmacol. 2009;12(8):1097-110.

75. Zamberletti E et al. Chronic blockade of $\mathrm{CB}(1)$ receptors reverses startle gating deficits and associated neurochemical alterations in rats reared in isolation. Br J Pharmacol. 2012;167(8):1652-64.

76. Zamberletti E et al. Long-lasting recovery of psychotic-like symptoms in isolation-reared rats after chronic but not acute treatment with the cannabinoid antagonist AM251. Int J Neuropsychopharmacol. 2012;15(2):267-80.

77. Niwa M, et al. Adolescent stress-induced epigenetic control of dopaminergic neurons via glucocorticoids. Science, 2013. 339 (6117): 335-339.

78. Geyer MA et al. Isolation rearing of rats produces a deficit in prepulse inhibition of acoustic startle similar to that in schizophrenia. Biol Psychiatry. 1993;34(6):361-72.

79. Koda $\mathrm{K}$ et al. Galantamine and donepezil differently affect isolation rearing-induced deficits of prepulse inhibition in mice. Psychopharmacology (Berlin). 2008;196(2):293-301.

80. Moller $\mathrm{M}$ et al. Social isolation rearing induces mitochondrial, immunological, neurochemical and behavioural deficits in rats, and is reversed by clozapine or N-acetyl cysteine. Brain Behav Immun. 2013;30:156-67.

81. McIntosh AL et al. The atypical antipsychotic risperidone reverses the recognition memory deficits induced by post-weaning social isolation in rats. Psychopharmacology (Berlin). 2013;228(1):31-42.

82. Lapiz MD et al. Influence of postweaning social isolation in the rat on brain development, conditioned behaviour and neurotransmission. Ross Fiziol Zh Im I M Sechenova. 2001;87(6):730-51.

83. Watson DJ et al. Blockade of dopamine $\mathrm{D}(3)$ but not $\mathrm{D}(2)$ receptors reverses the novel object discrimination impairment produced by post-weaning social isolation: implications for schizophrenia and its treatment. Int J Neuropsychopharmacol. 2012;15(4):471-84.

84. Koike $\mathrm{H}$ et al. Behavioral abnormality and pharmacologic response in social isolation-reared mice. Behav Brain Res. 2009;202(1):114 21. 
85. Colaianna $\mathrm{M}$ et al. Neuroendocrine profile in a rat model of psychosocial stress: relation to oxidative stress. Antioxid Redox Signal. 2013;18(12):1385-99.

86. Schiavone $\mathrm{S}$ et al. NADPH oxidase elevations in pyramidal neurons drive psychosocial stress-induced neuropathology. Transl Psychiatry. 2012;2:e111.

87. Muchimapura $\mathrm{S}$ et al. Isolation rearing in the rat disrupts the hippocampal response to stress. Neuroscience. 2002;112(3):697-705.

88. Turnock-Jones JJ et al. Increased expression of the NR2A NMDA receptor subunit in the prefrontal cortex of rats reared in isolation. Synapse. 2009;63(10):836-46.

89. Sestito RS et al. Effect of isolation rearing on the expression of AMPA glutamate receptors in the hippocampal formation. J Psychopharmacol. 2011;25(12):1720-9.

90. King MV et al. Increased dopamine D2High receptors in rats reared in social isolation. Synapse. 2009;63(6):476-83.

91. Ago Y, Matsuda T. Brain microdialysis of isolation-reared mice under freely-moving conditions. Nihon Yakurigaku Zasshi. 2003;122(2):135-40.

92. Lim AL, Taylor DA, Malone DT. A two-hit model: behavioural investigation of the effect of combined neonatal MK- 801 administration and isolation rearing in the rat. J Psychopharmacol. 2012;26(9):1252-64.

93. Suer C, Dolu N, Ozesmi C. The effect of immobilization stress on sensory gating in mice. Int J Neurosci. 2004;114(1):55-65.

94. Matrisciano $\mathrm{F}$ et al. Epigenetic modifications of GABAergic interneurons are associated with the schizophrenia-like phenotype induced by prenatal stress in mice. Neuropharmacology. 2013;68:184-94.

95. Koenig JI et al. Prenatal exposure to a repeated variable stress paradigm elicits behavioral and neuroendocrinological changes in the adult offspring: potential relevance to schizophrenia. Behav Brain Res. 2005;156(2):251-61.

96. Lee PR et al. Prenatal stress generates deficits in rat social behavior: Reversal by oxytocin. Brain Res. 2007;1156:152-67.

97. Holloway $\mathrm{T}$ et al. Prenatal stress induces schizophrenia-like alterations of serotonin $2 \mathrm{~A}$ and metabotropic glutamate 2 receptors in the adult offspring: role of maternal immune system. J Neurosci. 2013;33(3):1088-98

98. Blomstrom A, et al. Hospital admission with infection during childhood and risk for psychotic illness-A population-based cohort study. Schizophr Bull, 2013.

99. Kroll JL. New directions in the conceptualization of psychotic disorders. Curr Opin Psychiatry. 2007;20(6):573-7.

100. Lindley SE, Carlson E, Sheikh J. Psychotic symptoms in posttraumatic stress disorder. CNS Spectr. 2000;5(9):52-7.

101. Clarke MC et al. Sudden death of father or sibling in early childhood increases risk for psychotic disorder. Schizophr Res. 2013;143(23):363-6.

102. Rubino T, Parolaro D. Cannabis abuse in adolescence and the risk of psychosis: A brief review of the preclinical evidence. Prog Neuropsychopharmacol Biol Psychiatry, 2013.

103. Miettunen $\mathrm{J}$ et al. Association of cannabis use with prodromal symptoms of psychosis in adolescence. Br J Psychiatry. 2008;192(6):470-1.

104. Seeman $P$ et al. Brain receptors for antipsychotic drugs and dopamine: direct binding assays. Proc Natl Acad Sci U S A. 1975;72(11):4376-80.

105. Srisurapanont M, Kittiratanapaiboon P, Jarusuraisin N. Treatment for amphetamine psychosis. Cochrane Database Syst Rev. 2001;4, CD003026.

106. Yui K et al. Neurobiological basis of relapse prediction in stimulantinduced psychosis and schizophrenia: the role of sensitization. Mol Psychiatry. 1999;4(6):512-23.

107. Angrist BM, Gershon S. The phenomenology of experimentally induced amphetamine psychosis - preliminary observations. Biol Psychiatry. 1970;2(2):95-107.
108. Levy AD et al. Repeated exposure to cocaine produces long-lasting deficits in the serotonergic stimulation of prolactin and renin, but not adrenocorticotropin secretion. Eur J Pharmacol. 1993;241(2-3): 275-8.

109. Stevens KE, Fuller LL, Rose GM. Dopaminergic and noradrenergic modulation of amphetamine-induced changes in auditory gating. Brain Res. 1991;555(1):91-8.

110. Stevens KE et al. Effects of neonatal dopamine depletion on sensory inhibition in the rat. Pharmacol Biochem Behav. 1996;53(4):81723.

111. Maxwell CR et al. Phosphodiesterase inhibitors: a novel mechanism for receptor-independent antipsychotic medications. Neuroscience. 2004;129(1):101-7.

112. de Bruin NM et al. Differential effects of ketamine on gating of auditory evoked potentials and prepulse inhibition in rats. Psychopharmacology (Berlin). 1999;142(1):9-17.

113. Adler LE et al. Modulation of the gating of auditory evoked potentials by norepinephrine: pharmacological evidence obtained using a selective neurotoxin. Biol Psychiatry. 1988;24(2):179-90.

114. Segal DS, Kuczenski R. Escalating dose-binge treatment with methylphenidate: role of serotonin in the emergent behavioral profile. J Pharmacol Exp Ther. 1999;291(1):19-30.

115. Depatie L, Lal S. Apomorphine and the dopamine hypothesis of schizophrenia: a dilemma? J Psychiatry Neurosci. 2001;26(3):20320.

116. Depoortere R et al. Apomorphine-induced emesis in dogs: differential sensitivity to established and novel dopamine D2/5HT(1A) antipsychotic compounds. Eur J Pharmacol. 2008;597(1-3):34-8.

117. Dias FR et al. Opposite effects of low versus high dose haloperidol treatments on spontaneous and apomorphine induced motor behavior: evidence that at a very low dose haloperidol acts as an indirect dopamine agonist. Behav Brain Res. 2012;229(1):153-9.

118. Hikida $\mathrm{T}$ et al. Dominant-negative DISC1 transgenic mice display schizophrenia-associated phenotypes detected by measures translatable to humans. Proc Natl Acad Sci U S A. 2007;104(36):14501-6.

119. Jaaro-Peled $\mathrm{H}$ et al. Subcortical dopaminergic deficits in a DISC1 mutant model: a study in direct reference to human molecular brain imaging. Hum Mol Genet. 2013;22(8):1574-80.

120. Porteous DJ et al. The genetics and biology of DISC1 - an emerging role in psychosis and cognition. Biol Psychiatry. 2006;60(2): 123-31.

121. Axelrod J, Senoh S, Witkop B. O-Methylation of catechol amines in vivo. J Biol Chem. 1958;233(3):697-701.

122. Goldberg TE, Weinberger DR. Genes and the parsing of cognitive processes. Trends Cogn Sci. 2004;8(7):325-35.

123. Lachman HM et al. Human catechol-O-methyltransferase pharmacogenetics: description of a functional polymorphism and its potential application to neuropsychiatric disorders. Pharmacogenetics. 1996;6(3):243-50.

124. Chen $\mathrm{J}$ et al. Functional analysis of genetic variation in catechol-Omethyltransferase (COMT): effects on mRNA, protein, and enzyme activity in postmortem human brain. Am J Hum Genet. 2004;75(5): 807-21.

125. Cao YA et al. Nicotine normalizes event related potentials in COMT-Val-tg mice and increases gamma and theta spectral density. Behav Neurosci. 2012;126(2):332-43.

126. Shaikh $\mathrm{M}$ et al. Do COMT, BDNF and NRG1 polymorphisms influence P50 sensory gating in psychosis? Psychol Med. 2011;41(2):263-76.

127. Papaleo F, et al. Epistatic interaction between COMT and DTNBP1 modulates prefrontal function in mice and in humans. Mol Psychiatry, 2013.

128. Tan HY et al. Epistatic interactions of AKT1 on human medial temporal lobe biology and pharmacogenetic implications. Mol Psychiatry. 2012;17(10):1007-16. 
129. Nixon DC et al. Interactive effects of DAOA (G72) and catechol-Omethyltransferase on neurophysiology in prefrontal cortex. Biol Psychiatry. 2011;69(10):1006-8.

130. Sei $Y$ et al. Epistatic and functional interactions of catechol-omethyltransferase (COMT) and AKT1 on neuregulin1-ErbB signaling in cell models. PLoS One. 2010;5(5):e10789.

131. Tan HY et al. Catechol-O-methyltransferase Val158Met modulation of prefrontal-parietal-striatal brain systems during arithmetic and temporal transformations in working memory. J Neurosci. 2007;27(49):13393-401.

132. Nicodemus KK et al. Evidence for statistical epistasis between catechol-O-methyltransferase (COMT) and polymorphisms in RGS4, G72 (DAOA), GRM3, and DISC1: influence on risk of schizophrenia. Hum Genet. 2007;120(6):889-906.

133. Gould TJ et al. Sensorimotor gating deficits in transgenic mice expressing a constitutively active form of Gs alpha. Neuropsychopharmacology. 2004;29(3):494-501.

134. Wand $\mathrm{G}$ et al. The cAMP-protein kinase A signal transduction pathway modulates ethanol consumption and sedative effects of ethanol. J Neurosci. 2001;21(14):5297-303.

135. Numakawa $\mathrm{T}$ et al. Evidence of novel neuronal functions of dysbindin, a susceptibility gene for schizophrenia. Hum Mol Genet. 2004;13(21):2699-708.

136. Talbot $\mathrm{K}$ et al. Dysbindin-1 is reduced in intrinsic, glutamatergic terminals of the hippocampal formation in schizophrenia. J Clin Invest. 2004;113(9): 1353-63.

137. Vilella E et al. Association of schizophrenia with DTNBP1 but not with DAO, DAOA, NRG1 and RGS4 nor their genetic interaction. J Psychiatr Res. 2008;42(4):278-88.

138. Talbot K. The sandy (sdy) mouse: a dysbindin-1 mutant relevant to schizophrenia research. Prog Brain Res. 2009;179:87-94.

139. Tang J et al. Dysbindin-1 in dorsolateral prefrontal cortex of schizophrenia cases is reduced in an isoform-specific manner unrelated to dysbindin-1 mRNA expression. Hum Mol Genet. 2009;18(20): 3851-63.

140. Ji Y et al. Role of dysbindin in dopamine receptor trafficking and cortical GABA function. Proc Natl Acad Sci U S A. 2009;106(46): 19593-8.

141. Chen XW et al. DTNBP1, a schizophrenia susceptibility gene, affects kinetics of transmitter release. J Cell Biol. 2008;181(5): 791-801.

142. Nagai T et al. Dysfunction of dopamine release in the prefrontal cortex of dysbindin deficient sandy mice: an in vivo microdialysis study. Neurosci Lett. 2010;470(2):134-8.

143. Jentsch JD et al. Dysbindin modulates prefrontal cortical glutamatergic circuits and working memory function in mice. Neuropsychopharmacology. 2009;34(12):2601-8.

144. Talbot $\mathrm{K}$ et al. Dysbindin-1 is a synaptic and microtubular protein that binds brain snapin. Hum Mol Genet. 2006;15(20): 3041-54.

145. Guo AY et al. The dystrobrevin-binding protein 1 gene: features and networks. Mol Psychiatry. 2009;14(1):18-29.

146. Feng YQ et al. Dysbindin deficiency in sandy mice causes reduction of snapin and displays behaviors related to schizophrenia. Schizophr Res. 2008;106(2-3):218-28.

147. Pae CU et al. DTNBP1 haplotype influences baseline assessment scores of schizophrenic in-patients. Neurosci Lett. 2008;440(2): $150-4$.

148. Corvin A et al. A dysbindin risk haplotype associated with less severe manic-type symptoms in psychosis. Neurosci Lett. 2008;431(2):146-9.

149. Becker A et al. Ketamine-induced changes in rat behaviour: A possible animal model of schizophrenia. Prog Neuropsychopharmacol Biol Psychiatry. 2003;27(4):687-700.

150. Umbricht $\mathrm{D}$ et al. Ketamine-induced deficits in auditory and visual context-dependent processing in healthy volunteers: implications for models of cognitive deficits in schizophrenia. Arch Gen Psychiatry. 2000;57(12):1139-47.

151. Oranje B et al. The effects of a sub-anaesthetic dose of ketamine on human selective attention. Neuropsychopharmacology. 2000;22(3): 293-302.

152. Olney JW, Newcomer JW, Farber NB. NMDA receptor hypofunction model of schizophrenia. J Psychiatr Res. 1999;33(6): $523-33$.

153. Javitt DC. Glutamatergic theories of schizophrenia. Isr J Psychiatry Relat Sci. 2010;47(1):4-16.

154. Bickel S, Javitt DC. Neurophysiological and neurochemical animal models of schizophrenia: focus on glutamate. Behav Brain Res. 2009;204(2):352-62.

155. Ehrlichman RS et al. Deviance-elicited changes in event-related potentials are attenuated by ketamine in mice. J Cogn Neurosci. 2008;20(8):1403-14.

156. Heekeren $\mathrm{K}$ et al. Mismatch negativity generation in the human 5HT2A agonist and NMDA antagonist model of psychosis. Psychopharmacology (Berlin). 2008;199(1):77-88.

157. Deutsch SI, Hitri A. Measurement of an explosive behavior in the mouse, induced by MK-801, a PCP analogue. Clin Neuropharmacol. 1993;16(3):251-7.

158. Rogoz Z. Effect of co-treatment with mirtazapine and risperidone in animal models of the positive symptoms of schizophrenia in mice. Pharmacol Rep. 2012;64(6):1567-72.

159. Qi CT et al. Effect of GNTI, a kappa opioid receptor antagonist, on MK-801-induced hyperlocomotion and stereotypy in mice. Acta Pharmacol Sin. 2006;27(11):1401-8.

160. Harkin A et al. Modulation of MK-801-induced behaviour by noradrenergic agents in mice. Psychopharmacology (Berlin). 2001;154(2):177-88.

161. Hashimoto A et al. Mice lacking D-amino acid oxidase activity display marked attenuation of stereotypy and ataxia induced by MK-801. Brain Res. 2005;1033(2):210-5.

162. Ali SF, Newport GD, Bracha HS. Phencyclidine and (+)-MK-801induced circling preference: correlation with monoamine levels in striatum of the rat brain. Neurotoxicol Teratol. 1994;16(4):335-42.

163. Mathe JM et al. Prazosin inhibits MK-801-induced hyperlocomotion and dopamine release in the nucleus accumbens. Eur J Pharmacol. 1996;309(1):1-11.

164. Arai $\mathrm{S}$ et al. Involvement of pallidotegmental neurons in methamphetamine- and MK-801-induced impairment of prepulse inhibition of the acoustic startle reflex in mice: reversal by GABAB receptor agonist baclofen. Neuropsychopharmacology. 2008;33(13):3164-75.

165. Pietraszek $M$ et al. mGluR5, but not mGluR1, antagonist modifies MK-801-induced locomotor activity and deficit of prepulse inhibition. Neuropharmacology. 2005;49(1):73-85.

166. Pinault D. N-methyl d-aspartate receptor antagonists ketamine and MK-801 induce wake-related aberrant gamma oscillations in the rat neocortex. Biol Psychiatry. 2008;63(8):730-5.

167. Saunders JA, Gandal MJ, Siegel SJ. NMDA antagonists recreate signal-to-noise ratio and timing perturbations present in schizophrenia. Neurobiol Dis. 2012;46(1):93-100.

168. Bujas-Bobanovic $\mathrm{M}$ et al. Blockade of phencyclidine-induced effects by a nitric oxide donor. Br J Pharmacol. 2000;130(5):1005-12.

169. Volf $\mathrm{N}, \mathrm{Hu} \mathrm{G}, \mathrm{Li} \mathrm{M}$. Iptakalim preferentially decreases nicotineinduced hyperlocomotion in phencyclidine-sensitized rats: A potential dual action against nicotine addiction and psychosis. Clin Psychopharmacol Neurosci. 2012;10(3):168-79.

170. Hackler EA et al. Selective potentiation of the metabotropic glutamate receptor subtype 2 blocks phencyclidine-induced hyperlocomotion and brain activation. Neuroscience. 2010;168(1): 209-18.

171. Abekawa T et al. Effects of NRA0045, a novel potent antagonist at dopamine D4, 5-HT2A, and alpha1 adrenaline receptors, and 
NRA0160, a selective D4 receptor antagonist, on phencyclidineinduced behavior and glutamate release in rats. Psychopharmacology (Berlin). 2003;169(3-4):247-56.

172. Sircar R, Soliman KF. Effects of postnatal PCP treatment on locomotor behavior and striatal D2 receptor. Pharmacol Biochem Behav. 2003;74(4):943-52.

173. Haller J et al. Cannabinoid CB1 receptor dependent effects of the NMDA antagonist phencyclidine in the social withdrawal model of schizophrenia. Behav Pharmacol. 2005;16(5-6):415-22.

174. Javitt DC et al. Schizophrenia-like deficits in auditory P1 and N1 refractoriness induced by the psychomimetic agent phencyclidine (PCP). Clin Neurophysiol. 2000;111(5):833-6.

175. Ma J, Leung LS. Relation between hippocampal gamma waves and behavioral disturbances induced by phencyclidine and methamphetamine. Behav Brain Res. 2000;111(1-2):1-11.

176. Barros CS et al. Impaired maturation of dendritic spines without disorganization of cortical cell layers in mice lacking NRG1/ErbB signaling in the central nervous system. Proc Natl Acad Sci U S A. 2009;106(11):4507-12.

177. Bjarnadottir M et al. Neuregulin1 (NRG1) signaling through Fyn modulates NMDA receptor phosphorylation: differential synaptic function in NRG1+/- knock-outs compared with wild-type mice. J Neurosci. 2007;27(17):4519-29.

178. $\mathrm{Gu} \mathrm{Z}$ et al. Regulation of NMDA receptors by neuregulin signaling in prefrontal cortex. J Neurosci. 2005;25(20):4974-84.

179. Hahn CG et al. Altered neuregulin 1-erbB4 signaling contributes to NMDA receptor hypofunction in schizophrenia. Nat Med. 2006;12(7):824-8.

180. Li B et al. The neuregulin-1 receptor erbB4 controls glutamatergic synapse maturation and plasticity. Neuron. 2007;54(4):583-97.

181. Ehrlichman RS et al. Neuregulin 1 transgenic mice display reduced mismatch negativity, contextual fear conditioning and social interactions. Brain Res. 2009;1294:116-27.

182. Mohn AR et al. Mice with reduced NMDA receptor expression display behaviors related to schizophrenia. Cell. 1999;98(4):427-36.

183. Yu Z et al. GABA transporter-1 deficiency confers schizophrenialike behavioral phenotypes. PLoS One. 2013;8(7):e69883.

184. Llado-Pelfort L et al. 5-HT1A receptor agonists enhance pyramidal cell firing in prefrontal cortex through a preferential action on GABA interneurons. Cereb Cortex. 2012;22(7):1487-97.

185. Szabadics J et al. Excitatory effect of GABAergic axo-axonic cells in cortical microcircuits. Science. 2006;311(5758):233-5.

186. Gouzoulis-Mayfrank E et al. Psychological effects of (S)-ketamine and $\mathrm{N}, \mathrm{N}$-dimethyltryptamine (DMT): a double-blind, cross-over study in healthy volunteers. Pharmacopsychiatry. 2005;38(6):301-11.
187. Halberstadt AL, Geyer MA. Serotonergic hallucinogens as translational models relevant to schizophrenia. Int J Neuropsychopharmacol. 2013;16(10):2165-80.

188. Carhart-Harris RL et al. Psychiatry's next top model: cause for a rethink on drug models of psychosis and other psychiatric disorders. J Psychopharmacol. 2013;27(9):771-8.

189. Vollenweider FX et al. Psilocybin induces schizophrenia-like psychosis in humans via a serotonin-2 agonist action. Neuroreport. 1998;9(17):3897-902.

190. Santini MA et al. Enhanced prefrontal serotonin 2A receptor signaling in the subchronic phencyclidine mouse model of schizophrenia. J Neurosci Res. 2013;91(5):634-41.

191. Trichard C et al. Binding of antipsychotic drugs to cortical 5-HT2A receptors: a PET study of chlorpromazine, clozapine, and amisulpride in schizophrenic patients. Am J Psychiatry. 1998;155(4):505-8.

192. Shapiro DA et al. Aripiprazole, a novel atypical antipsychotic drug with a unique and robust pharmacology. Neuropsychopharmacology. 2003;28(8):1400-11.

193. Leysen JE et al. Risperidone: a novel antipsychotic with balanced serotonin-dopamine antagonism, receptor occupancy profile, and pharmacologic activity. J Clin Psychiatry. 1994;55(Suppl): $5-12$.

194. Martin P et al. Rodent data and general hypothesis: antipsychotic action exerted through 5-Ht2A receptor antagonism is dependent on increased serotonergic tone. J Neural Transm. 1998;105(4-5):36596.

195. Nandra KS, Agius M. The differences between typical and atypical antipsychotics: the effects on neurogenesis. Psychiatr Danub. 2012;24 Suppl 1:S95-9.

196. Weiner DM et al. 5-hydroxytryptamine2A receptor inverse agonists as antipsychotics. J Pharmacol Exp Ther. 2001;299(1):268-76.

197. van den Buuse $M$ et al. Altered N-methyl-D-aspartate receptor function in reelin heterozygous mice: male-female differences and comparison with dopaminergic activity. Prog Neuropsychopharmacol Biol Psychiatry. 2012;37(2):237-46.

198. Proitsi P et al. Association of serotonin and dopamine gene pathways with behavioral subphenotypes in dementia. Neurobiol Aging. 2012;33(4):791-803.

199. Luoni A et al. Behavioural and neuroplastic properties of chronic lurasidone treatment in serotonin transporter knockout rats. Int $\mathrm{J}$ Neuropsychopharmacol. 2013;16(6):1319-30.

200. Daws LC, Gould GG. Ontogeny and regulation of the serotonin transporter: providing insights into human disorders. Pharmacol Ther. 2011;131(1):61-79. 